\title{
Sobre "Todos los Fuegos el Fuego"
}

\section{Por ANTONIO CORNEJO POLAR}

Cada texto literario impone un modo específico de conocimiento, tanto porque es único e incomparable, como querían Croce, Vossler, Spitzer o los Alonso, quienes incluso exageraban el concepto de unicidad det a obra al no vero minimizar las categorías genéricas que en ella se actualizan, cuanto, sobre todo, porque es única la relación lector-bbra, relación de la cual depende, en última instancia, el significado mismo del texto: extraño trompo, según Sartre, que sólo existe cuando está en movimiento. ${ }^{1}$

"Todos los fuegos el fuego"2 ordena, así la adopción de una postura crítica específica; en este caso, la que parte del análisis de las dos historias que se narran en el texto, tratando de averiguar la razón de su presencia dentro de una sola unidad estética, lo que equivale a plantearse problemas relativos a las significaciones de ambas unidades y a las funciones que cumplen con respecto al todo.

1) SARTRE, Jean-Paul: ¿Qué es la literatura?. Bs. Aires. Nova, 1950, p. 71

2) CORTAZAR, Julio: Todos los fuegos el fuego, Bs. Aires, Sudamericana, 1967 (5 ed.) De aquí en adelante citaremos por las siglas T. F. F., aludiendo siempre al cuento de este título, no al libro que lleva su nombre.

Letras, Lima, $40(80.81): 71.83,1968$. 


\section{LAS DOS HISTORIAS}

La lectura de T.F.F. revela que el cuento está conformado sobre dos anécdotas: la del procónsul y su esposa Irene, espectadores de un sangriento combate entre gladiadores, y la de Roland y Jeanne, personajes actuales que, unidos a Sonia, forman un tradicional triángulo amoroso.

La primera anécdota, mucho más densa que la segunda en lo que atañe a su configuracićn argumental, nos enfrenta a una escena suficientemente explícita. El procónsul ha organizado un espectáculo en el circo de su jurisdicción provincianá $\mathrm{y}$, dentro de ese programa, ha incluído una sorpresa: el combate de Marco, gladiador famoso, contra un reciario gigantesco. El pueblo agradece la organización de este espectáculo, montado, sobre todo, para averiguar las reacciones de la ines. crutable Irene, alguna vez descubierta por el procónsul deseando a Marco: en realidad apenas "una doble mirada inútil sobre el cadáver de un tracio diestramente muerto de un tajo en la garganta". (p. 153) En el combate mueren los dos luchadores. Poco después, cuando el procónsul, su comitiva y el pueblo se retiran del circo, estalla un incendio y se insinúa la muerte de los protagonistas: "no podremos salir (...) están amontonados ahí abajo (los espectadores) como animales". dice uno de ellos. (p. 165)

La segunda historia es narrada menos explícitamente. El lector escucha una conversación telefónica "entre Roland y Jeanne (que tiene como fondo otra conversación interferida: alguien recita cifras, interminablemente), de la que se desprende que sus relaciones eróticas acaban de ser destruídas por Sonia, ahora amante de Roland. Ella ha informado a Jeanne de todo: "... era natural que Sonia no se conformara con un mensaje cifrado, que quisiera decirlo con todas sus letras, saboreándolo hasta el último", leemos en el texto. (p. 158) Al terminar la conversación telefónica Sonia entra al departamento de Roland. Charlan, beben, fuman, se adormecen: "Sonia es la primera en adormecerse y él le quita muy despacio el cigarrillo de la boca, lo junta con el suyo y los abandona en la mesa, resbalando contra Sonia en un sueño pesado y sin imágenes". (p. 164) Despiertan envueltos por el fuego del incendio que los cigarrillos han producido: "... todavía gritan, cada vez más débilmente, cuando el carro de bomberos entra a toda máquina por la calle atestada de curiosos" (pp. 165-166) 


\section{PROXIMIDAD Y DISTANCIA}

A primera vista ambas historias son paralelas, aunque se narren intercalando episodios de una y otra, especialmente porque hay entre ellas distancias muy grandes: la cronológica, por ejemplo. Sin embargo, los incendios que consumen el coliseo y el departamento de Roland son indicios de que ambas historias pueden tener alguna vinculación profunda, ser manifestaciones de un mismo orden de cosas.

Un texto posterior de Cortázar nos dice de su preferencia por encontrar la unidad de las diversidades, las correlaciones hondas que puede haber entre conjuntos aparentemente heterogéneos:

"Aludo a la sospecha de arcaica raíz mágica según la cual hay fenómenos e incluso cosas que son lo que son y como son porque, de alguna manera, también son o pueden ser otro fenómeno u otra cosa; y que la acción recíproca de un conjunto de elementos que se dan como heterogéneos a la inteligencia no sólo es susceptible de desencadenar interacciones análogas en otros conjuntos aparen temente disociados del primero, como lo entendía la magia simpática y más de cuatro gordas agraviadas que todavian clavan alfileres en figurillas de cera, sino que existe identidad profunda entre uno y otro coniunto, por más escandaloso que leoparezcal al intelecto" $\left.{ }^{3}\right)$.

Tal "sospecha", que en Cortázar Hlega'sa" ser una obsesión, vinculándolo así al Borges de "Ficciones" por ejemplo, permite experiencias de esta índole:

"Cuántas veces he sentido que una fulgurante combinación de fútbol (sobre todo si la hacía River Plate, equipo al que fui fiel en mis años de buen porteño) podía estar provocando una asociación de ideas en un físico de Roma, a menos que naciera de esa asociación o, ya vertiginosamente, aue físico y fútbol elementos de otra operaciór que podía estarse cumpliendo en una rama de cerezo de Nicaragua, y las tres cosas, a su vez..." ( $\left.{ }^{4}\right)$.

Numerosos relatos de Cortázar están construídos sobre esquemas que se explican en esta creencia, basada, por lo de-

3) CORTAZAR, Julio. Yo podría bailar ese sillón -dijo Isidora. En La vuelta al día en ochenta mundos, México, siglo XXI, 1967, p. 49.

4) Ibid. p. 52. 
más, en el conocimiento de ciertas filosofías orientales, dentro de cuyo contexto es posible pensar, por ejemplo, que "somos mutuamente la ilusión el uno del otro"5 Nos referimos, sea el caso, a "Una flor amarilla" y a "La noche boca arriba", ambos de "Final del iuego", o a la relación de "doblaje" entre Oliveira y Traveler ( $\mathrm{y}$ también hasta cierto punto entre la Maga y Talita) que se insinúa por momentos en "Rayuela", según lo ya advertido por Luis Harss. ${ }^{6}$

A partir de estas incisiones contextuales, que en ningún caso pueden ser consideradas mas que como supuestos de la investigación, es lícito indagar hasta qué punto la estructura de T.F.F. importa tal tipo de correlaciones, cuáles son éstas, cómo funcionan y qué sentido tienen.

\section{ZONAS DE INTERSECCION}

En las primeras páginas de T.F.F. el paso de una historıa a la otra (que llamaremos " $A$ " - la del procónsul_ y " $\mathrm{B}$ " - la de Roland) - corresponden al paso de un párrafo a otro. Lá identidad diferencial de ambas anécdotas queda así, aunque externamente, definida. Este mismo deslinde se subraya, ahora en otro nivel, porque las harraciones de "B" se inician con menciones relativas al teléfono, menciones que sacuden al lector, ya ambientado en la lejanía histórica de " $\mathrm{A}$ " (circo, procónsul, gladiadores, etc.) Esta bifurcación de las anécdotas en párrafos separados funciona cabalmentecen las páginas ini.. ciales de T.F.F., en sus cuatroiprimeros pámafos (de un total de doce) para ser más concretos.

El esquema se modifica luego. A partir del párrafo quinto ia separación entre las dos historias queda marcada sólo por puntos seguidos, de suerte que, en general, cada párrafo incluye narraciones correspondientes a " $A$ " y " $B$ ", exceptuándose los párrafos sexto y décimo que abarcan, como al comienzo, una sola anécdota. Hay que advertir que la norma es la bipartición del párrafo, aunque el octavo y el duodécimo sufran parcelaciones más numerosas, produciéndose, entonces, más de dos cambios de tema por párrafo. El esquema del duodécimo sería, por ejemplo, el siguiente: B-A-B-A-B.

Es claro que la presencia de las dos historias dentro de una unidad formal como el párrafo hace más visibles los suti-

5) HARSS, Luis. Los nuestros, Bs. Aires. Sudamericana, 1966 p. 267.

6) Ibid. p. 281 . 
ies hilos que cruzan ambas anécdotas y tienden a su homologación, a la par que cambia la actitud del lector, antes sorprendido por los abruptos cambios de un mundo a otro, $y$ ahora, poseedor de una presunta clave (la unidad de las dos vetas narrativas), asombrado ante la aparición de una tupida red de consonancias, todas las cuales, aunçue a veces oscura. mente, reafirman la unidad semántica de T.F.F.

\section{LOS COMBATES}

Aconsejan los estructuralistas que se inicie el acoso a un objeto estético (en realidad a cualquier objeto) tratando dt delimitar las unidades internas que lo conforman. Esta actividad de "recorte", para usar el léxico de Barthes, ${ }^{7}$ se facilita grandemente en el caso de T.F.F., donde las unidades internas se evidencian desde la primera lectura en orden a la distinción -ya hecha- de las dos historias. El sopeso de este obvio distingo permitirá saber si las diferencias entre una y otra corresponden a una magnitud tal que impide toda homologación o si, por el contrario, esas mismas diferencias son las que permiten efectuar tareas comparativas, supuesto - como es indudable - que dos situaciones idénticas son incomparables, lo mismo que dos conjuntos esencialmente distintos.

Un fragmento de T.F.F. permitirá indagar, sobre el entramado de la creación misma, las correlaciones específicas entre ias dos unidades:

\section{"Jorge Puccinelli Converso"}

"Roland bebe un trago de coñac. Siempre le ha gustado escoger sus palabras, evitar los diálogos superfluos Jeanne repetirá dos, tres veces cada frase, acentuándola de una manera diferente; que habla, que repita mientras él prepara un minimo de respuestas sensatas que pongan or. den en ese arrebato lamentable. Respirando con fuerza se endereza después de una finta y un avance lateral: algo le dice que esta vez el nubio va a cambiar el orden del ataque, que el tridente se adelantará al tiro de la red". (p. 159).

El lector se enfrenta aquí a dos movimientos: uno físico, por lo demás evidente ("fintas", "avance lateral"), y otro más bien psíquico, expresado por las reiteraciones de las frases de Jeanne, no transcritas en el texto). Hay algo que nos dice,

7) BARTHES, Roland. Estudios Críticos, Barcelona, Seix Barral, 1967, p. 258. 
sordamente, que uno y otro movimiento son de un mismo orden, aunque hacia afuera el parentesco no sea del todo visible.

En efecto, dentro del desarrollo total de T.F.F., cabe advertir que la conversación telefónica es también, a su modo, un combate, sólo que en un caso estamos ante los hechos, ell su brutalidad más desnuda, y en otşo ante una lucha "inte. rior", por decirlo de alguna manera, que se tamiza por darse dentro de un ámbito "civilizado" (".... al fin y al cabo somos gente civilizada", dice Roland - p. 160) donde la palabra corresponde al tridente y a la red.

Por esto no llama la atenciún que apenas la conversación entre Roland y Jeanne termina ("... el silencio en la línea parece tenderse como un arco" — p. 161), el narrador, pasando ai relato de " $B$ ", nos diga:

"Paralizado, sabiéndose incapaz de evitar la red que no tardará en envolverlo, Marco hace frente al gigante nubio, la espada demasiado corta inmóvil en el extremo del bra. zo tendido..." ( $p$. 161).

También paralizada, vencida, está Jeanne, envuelta en la espesa red del silencio. La conversación y el combate tienen, pues, una dinámica similar $y$, sobre todo, una similar connoiación. Son, por consiguiente, homologables.

Otras correlaciōnesedeudetalleiapuntansen esta misma dirección. La vociferación de la plebe (en "A") se confunde con la "crepitación de las comunicaciones mezcladas" (en " $B$ ") y ambas ceden al silencio para dar ingreso a los personajes; en "A": "En un brusco silencio de expectativa que lo recorta con una precisión implacable, Marco avanza hacia el centro..." (p. 150); mientras que en "B": "... alguien dicta cifras, de golpe un silencio todavía más oscuro en esa oscuridad que el teléfono vuelca en el ojo del oído. 'Hola', repite Roland..." (Id) También situaciones correlativas: Irene (en "A") "bebe un largo sorbo, que parece llevarse con su leve perfume el olor espeso y penetrante de la sangre y el estiércol" (p. 150), a la par que (en " $\mathrm{B}$ ") "Roland bebe una copa de coñac" mientras piensa en la respuesta que dará a Jeanne para evitar todo "arrebato lamentable". (p. 159)

Al igual que éstos, citados como ejemplos, hay muchos otros elementos en T.F.F. que bien pueden servir para subra- 
yar las correlaciones entre las dos historias. Los referidos son suficientes, empero, para los fines de este parágrafo.

\section{LAS FUERZAS OSCURAS}

Desde otro punto de vista, conviene advertir que Jeanne llama a Roland sin tener objetivo alguno. Las revelaciones de Sonia le son suficientes, tanto, que apenas dice unas pocas frases, frases que se agotan expresivamente sin cumplir ninguna función realmente apelativa. Marco, por su parte, tiene una viscosa y oscura certidumbre de ser derrotado. Ha escuchado palabras enigmáticas y soñado escenas misteriosas que de pronto, en pleno combate, revelan su fúnebre sentido:

“. . ahora sí, más acá de toda razón, sabe que el procónsul no le pagará con monedas de oro, adivina el sentido del pez y las columnas rotas. Y a la vez poco le importa lo que va a suceder entre el reciario y él, eso es e! oficio y los hados, pero su cuerpo sigue contraido como si tuviera miedo..." (p. 152).

Marco y Jeanne actúan al margen de toda conciencia teleológica, por una parte; por otra, obedecen ciegamente a oscuras fuerzas que sobrepasan su capacidad de decisión. Marco y el reciario luchan sin más rázón que la de obedecer a un estatuto que se les ha impuesto, estatuto sagrado que jamás cuestiones: los hados y el oficio. Jeanne y Roland participan también de una especierde Frito:inella, oaunrsintiendo vergüenza ("Jeanne ha tenido una sensación de ridículo, de que va a decirle a Roland eso que exactamente la incorporará a la galería de las plañideras telefónicas" - p. 153), se deja llevar por un impulso más fuerte, incontenible, y empieza una conversación sin objetivos. Las reiteradas referencias al "tubo de pastillas" que tiene en la mano pp. 153, 154, 156, 162), bien pudieran aludir a su decisión de suicidarse.

Tal vez se explique aquí ese tono cuasi litúrgico que el lector cree descubrir en los movimientos de los gladiadores y en la conversación de los amantes, ejecutores-unos y otros - de ritos cuyo sentido escapa a los mismos oficiantes. Apunta en este sentido la solemne y fría minucia con que Cortázar relata la lucha entre Marco y el reciario, sin excusar ciertas sutiles formas de reiteración ("... mientras la espada (a), demasiado corta resuena (b) inutilmente (c) contra el asta" -p. 159) y utilizando, aunque excepcionalmente, comparacio. 
nes suntuosas: "... para protegerse del rio brillante que escapa como un rayo de la mano del nubio". (p. 159)

\section{LO HUMANO NOS ES AJENO}

Marco se enfrenta al reciario, a una fuerza ciega, atrozmente libre de todo pensamiento, que matará (o será muerto) sin que un sólo pálpito humano lo remezca. Marco, asimismo, actúa casi mecánicamente, respondiendo a las normas de su oficio, sin que en él haya lugar más que para las reacciones automáticas: “... pero Marco no comprenderá, torvo y silencioso y máquina..." (p. 153), leemos en el texto.

A su vez Jeanne está frente a la indiferencia de Roland, ante una dura costra que defiende ya no la vida (estamos erı el nivel de la "civilización", tan caro a Roland) sino, para decirlo de alguna manera, el confort espiritual. Se quiere evitar el desagrado que produce el dolor y las quejas del otro, el poco elegante recurso de las lágrimas. Por esto, mientras oye a Jeanne, Roland "suspira, desecha las respuestas que podrian alargar hasta el bostezo un diálogo tedioso". (p. 160)

En uno y otro caso la violencia aumenta en crueldad porque quienes la viven (hiriéndose, matándose) han alienado su condición humana - a excepción, tal vez, de Jeanne, la víctima. Sucede que esta violencia se produce sin que el odio domine a sus actores; es una violencia fria, ingrávida, gratuita. Es también, por esto mismó, ferozcl Marco y elr reciario se matarán sin conocerse siquiera, igual que hubieran tenido que matar o morir en otro combate, frente a otro adversario, siempr? desconocido, indiferente. Y Roland y Jeanne tampoco sabrán nunca la razón de su amor y la razón de su ruptura: "Por" favor - dice Roland - en estos cásos nadie entiende gran cosa, querida, y además no se gana nada con entender". (p. 158)

En el fondo de este sordo conflicto late el problema de la incomunicación. Es obvio que entre los gladiadores no cabe comunicación alguna: ellos ni siquiera la pretenden. Jeanne y Roland, al contrario, no hacen más que hablar; sin embargo, tampoco se comunican. Ya hemos indicado que Jeanne usa al lenguaje sólo para expresarse (por eso su hablar es tan reiterativo), sabiendo de antemano que no llegará a la intimidad de Roland. Cada personaje está enquistado en sí mismo, ajeno en absoluto al existir de los otros, y la identidad de cada cual - clímax de la inhumanidad- no es más que una semivigilia 
donde las cosas suceden oscuramente, guiadas por fuerza's cuya explicación ni siquiera se intenta y en cuyas consecuencias el hombre, claudicante y vencido, no tiene otro remedio que sumergirse.

Tal vez la única comunicación que se realiza en T.F.F. sea, en un sarcasmo terrible, la de la conversación telefónica interferida; esa interminable recitación de cifras que Roland y Jeanne escuchan en sus largos momentos de silencio: "quizás esas cifras digan más, sean más que cualquier discurso para el que las está escuchando atentamente", piensa Jeanne (p. 158) O también, aunque estirando tal vez con exceso el hilo hermenéutico, la conversación entre Jeanne y Sonia ("... era natural que Sonia no se conformara con un mensaje cifrado, que quisiera decirlo con todas las letras, saboreándolo hasta lo último" - p. 158), de donde podría pensarse que sólo el ma!, el deseo de herir (Sonia iustifica su actuar en el placer que le proporciona el dolor de Jeanne - p. 163), puede hacer que un hombre acceda a la intimidad de otro: la comunicación sólo es posible entre víctimas v verdugos, sería, en este contexto, la macabra conclusión final. 8

\section{CORRELACIONES MULTIPLES}

Lo dicho hasta aquí podría hacernos pensar en construír esquemas simétricos donde los rersonajes $y$ sus acciones emparejen cabalmente. No es así, sin embargo. Sería falso afir. mar, por ejemplo, que $\mathrm{Marco}$ es l correlativo a Jeanne como il reciario lo es a Roland, en cuanto, sea el caso, Roland es también el procónsul, sin dejar de vincularse con el reciario, quien a su vez, evidentemente, se refiere a Sonia.

En efecto, la historia "A", con sus tres personajes centrales, el procónsul, Marco y el reciario, funciona como una contienda entre los dos últimos bajo el poder del primero, quien, por su parte, lucha también con Irene. La historia "B", en cambio, aunque también con tres personajes básicos, Roland, Jeanne y Sonia, funciona de otra manera: Roland y Sonia hieren a Jeanne, cuya correlación con Marco sí parece exacta, pero Roland cubre un campo doble, con respecto a la primera historia, porque él es, por una narte, el procónsul y, por otra, al mismo tiempo, el reciario. El combate con Jeanne (la conversación es una contienda) pero, a la par, genera la luchia

8) CORTAZAR, Julio. Relaciones sospechosas. En: La vuelta al... Op. cit. p. 162 
entre ella y Sonia, teniendo así, hasta cierto punto al menos: la función que cumple en "A" el procónsul.

\section{FUNCION CONTEXTUAL REVERSIBLE}

Pero hay más: el significado de las dos historias supone no un equilibrio de simetría, que ya se vio falso, sino una relación de mutua implicancia, de suerte que el significado de cualquiera de ellas está condicionado por el significado de la otra. Hasta cierto punto está en una relación sintáctica similar a la que se produce entre una unidad léxica y su contexto lingüístico, en la medida en que esa unidad precisa y define sı propio sentido en orden a la presión que sobre ella ejerce el contexto.

Así, por ejemplo, la historia de Roland y Jeanne cobra tono trágico (desligándose de su aparente intrascendencia en cuanto tradicional triángulo amoroso) gracias a la historia de Marco. Funciona ésta como corolante de aquélla y logra re.velar, con fuerza incuestionable, la médula trágica que se esconde en la aparentemente inocua conversación telefónica. Es claro que tal se produce a nivel general (el sentido total de una historia revela el de la otra, enriqueciéndolo) cuanto a nivel de correlaciones de detalle (un gesto de " $A$ " esclarece una escena de "B", o viceversa), lo que importa una múltiple funcionalidad semántica, en cuanto al significado general es mucho más que la suma de los significados parciales.

\section{DIALECTICA DE LO UNO Y LO DIVERSO}

De esta suerte queda también marginada toda posibilidad de ver en T.F.F. un juego de símbolos reversibles; esto es, de interpretar cualquiera de las historias como símbolo de la otra, en relación que pudiera invertirse. ${ }^{9}$ Barthes afirma que toda relación simbólica equivale a la negación de la forma (uno de los niveles del símbolo) en la medida en que ésta no será más que algo determinado. ${ }^{10} \mathrm{Y}$ en T.F.F. no hay manera de interpretar una de las dos historias (cualquiera) como forma de la otra; por el contrario, ambas tienen identidad propia, ambas son semánticamente válidas.

9) No se escapa que T. F. F, pudiera ser alguno de esos brillantes juegos estéticos frecuentes en Cortázar, y que pudiera interpretarse dentro del esquema sueño-rea lidad, también frecuente en nuestro autor, pensando ( $y$ la posibilidad es sugestiva) en el ilativo "entonces" que, sintomáticamente, une los episodios de los incendiüs (p. 165), en cuyo caso el texto tendria quo ver, posiblemente, con las preocupacion.ss orientalistas de su autor, ya mencionadas.

10) BARTHES, R. Op. cit. p. 247, ss., esp. p. 250 
La estructura de T.F.F. se plantea, así, como una relación dialéctica entre unidad (hemos intuido que las dos historias aluden a un fondo común) y diversidad (en cuanto ambas tienen su propia identidad diferencial). El esquema sería totalmente inoperante, o correspondería a otro objeto estético, si cualquiera de los extremos alcanzara su plenitud: si la unidad fuera tal que una historia estuviera representada simbólicamente por la otra, sea el caso, o si, en el extremo opuesto, no existiera más que paralelismo entre ambạs anécdotas, de suerte que entre una y otra no existiera más vínculo que el de la yuxtaposición, por ejemplo.

Pero ya sabemos que esto no es así. Sabemos que existen correlaciones específicas entre " $\mathrm{A}$ " $\mathrm{y}$ " $\mathrm{B}$ " y que su unidad se hace manifiesta en la escena final de los incendios, pero, al mismo tiempo, sabemos que esta identidad no es total porque, bastará este ejemplo, los personajes de una historia abarcali funciones más amplias o más restringidas que los personajes correlativos de la otra historia. Por consiguiente, las dos historias son, al mismo tiempo, una y diversas: son dos gestos de un mismo rostro.

\section{VARIABLES Y EJE SEMANTICO}

Al precisar la relación entre lo único y lo diverso podemos comprender que los esquemas del estructuralismo pueden ser idóneos para descubrirl la indole semánticasy la organización funcional de T.F.F. cuya creación sería, por otra parte, una muestra esclarecedora de la actividad estructuralista en el orden de la producción estética.

En efecto, en la medida en que las dos historias son homologables (o al contrario: no son simples otredades), bien pudieran pensarse en ellas como variables de un solo eje semántico. En este sentido hasta el título del relato nos serviría para proponer que su estructura responde ef́ectivamente a un juego de variables (los fuegos) correlativas a un eje semántico singular (el fuego) .

La riqueza significativa de T.F.F., entrevista en las páginas anteriores, nos aconseja no intentar siquiera una interpreta.ción con pretensiones de univocidad, muy especialmente porque el texto, como todos los de Cortázar, está concebido y eje-

11) Ibid. p. 9. 
cutado en orden a la creación de una "obra abierta", donde será el lector el encargado de decir, como piensa Barthes, "la última palabra".11 Cabe, en cambio, ofrecer una visión final que, al describir la funcionalidad semántica del texto, implique, aunque táctica y parcialmente, una posibilidad de interpretación, interpretación tan "abierta" como la obra misma.

Parece claro, por lo pronto, que la organización de T.F.F. importa tres instancias: "el fuego" —como eje semántico-, "los fuegos" - como variables-, ambas ya dichas, y "los incendios" - como plasmaciones argumentales de las variables $y$, por tanto, del eje.

Las escenas finales -el fuego consumiendo los dos escenarios y aniquilando a los protagonistas - tienen, sin duda, un tono apocalíptico. El pánico de los espectadores en el circo y los gritos de los amantes rubrican el clima de violencia, brutal en un caso, sutil en otro, que domina el relato en su integridad. Los incendios importan, así, una violencia última, global, abarcadora de todas y cada una de las violencias específicas que han desfilado delante del lector. Representan, en este sentido, la exacerbación apocalíptica de uno de los significados ya dichos.

Sin embargo, los incendios no agotan su virtualidad significativa en esta suerte de climax. Ellos modifican la índole misma del relato (en cuanto será imposible entenderlo como narración realista de concreción no trascendente) y modifican también toda interpretación primaria (crueldad, alienación, incomunicación, etc.) Esta modificación, aunque resulte tal vez extraño, no inhibe la importancia ni la significación de las unidades menores (Marco como individuo, la conversación tetefónica como manifestación de la incomunicación de los hombres, etc.) en la medida en que organiza sobre ellas un nuevo nivel semántico.

Se trata, en parte al menos, de la creación de una nueva perspectiva desde la cual lo anecdótico y las significaciones parciales, sin sufrir merma en cuanto tales, alcanzan estratos más altos y más ricos en cuanto más complejos, hasta el punto de reorganizar todo el relato en orden a esa revelación final que proponen las escenas de los incendios.

Dentro de la nueva organización que imponen las páginas 
últimas del cuento, ${ }^{12}$ es dable encontrar una doble proyección. Se trata, por una parte, de la descripción del hombre, de su existencia; por otra, de una requisitoria en su contra. Prevalece en ambas la oscura angustia de la existencia sometida a un estatuto cosificador, alienante, dentro de cuyos límites el hombre no podrá serlo con autenticidad e impedirá que los otros, sus semejantes, puedan referirse a él en términos humanos. La excentricidad del estatuto, impuesto al hombre desde fuera, no obsta para que el hombre mismo quede contaminado y culpable: a veces su aquiescencia, a veces su colaboración, nunca el gesto decisivo que revele la capacidad de existir humanamente.

En este sentido el fuego tiene algo de su religioso carácter punitivo, pero, sobre todo, funciona como manifestación tangible del aniquilamiento y la desintegración del hombre. El fuego no es tanto sí mismo cuanto su efecto: la destrucción. Las escenas últimas equivalen a un gran holocausto final, perfectamente absurdo, donde todos y todo se pierde, sin que nadie pueda conocer la razón última de una existencia sin más salida que la destrucción. Víctimas y-verdugos, actores y espectadores, inocentes y culpables, hombres de ayer y de hoy, todos, sujetos a la ley de la incomunicación, de la crueldad, de la violencia y de la alienación, ejecutan. algo así como una litúrgica danza macabra antes de ser consumidos por el fuego. Un extraño fuego que destruye sin iluminar.

\section{«Jorge Puccinelli Converso»}

12) Técnica usada en Cortázar. Cf Continuidad de los parques. En: Final del juego. Bs. Aires, Sudamericana, 1968 (6 ed.) p. 9.11. 